\title{
Aislamiento de Sporothrix pallida y Trichophyton rubrum en onicomicosis de mano
}

\author{
(Isolation of Sporothrix pallida and Trichophyton rubrum in hand onychomycosis)
}

Rodrigo Cruz Ch. ${ }^{1 *}$, Peggy Vieille $0^{2}$., Daniel Opazo $D^{3}$., Ignacio Soto $R^{4}$.

${ }^{1}$ Cátedra de Micologia Universidad de Valparaíso, Infectologia Hospital Carlos van Buren de Valparaíso. ${ }^{2}$ Micologia y Anatomía Patológica Universidad de Valparaíso.

${ }^{3}$ Alumno Medicina Universidad de Valparaíso.

${ }^{4}$ Alumno Medicina Universidad de Valparaíso.

Recibido: $15 / 05 / 2013$

*Autor para correspondencia: rcruzchoappa@gmail.com

Aprobado: 03/06/2013

Palabras clave: Sporothrix pallida, Trichophyton rubrum, onicomicosis.

Key words: Sporothrix pallida, Trichophyton rubrum, onychomycosis.

\section{RESUMEN}

Se presenta un caso de onicomicosis de mano, de la cual se aisló en repetidas ocasiones Sporothrix pallida y Trichophyton rubrum. Se discute sobre los principales agentes de onicomicosis, el rol de los hongos ambientales y del aislamiento de S.pallida en este y en otro tipo de muestras.

\section{INTRODUCCION}

La infeccion de las uñas causada por hongos u onicomicosis (OM) es frecuente en la población. Diferentes estudios muestran una prevalencia entre el $2-18 \%$ y donde Trichophyton rubrum es el principal agente etiologico, tanto en uñas de manos como de pies $(1,2)$.

Las levaduras siguen en frecuencia a los dermatofitos, siendo las pertenecientes al género Candida las más frecuentes, especialmente $\boldsymbol{C}$. parapsilosis y C. albicans $(3,4)$.

Los aislamientos de hongos ambientales causantes de OM son cada vez más frecuentes, siendo predominantes varias especies pertenecientes a Fusarium, Scopulariopsis, Aspergillus y Acremonium, entre otros géneros (5).

Sporothrix schenckii complex comprende un grupo de hongos dimórficos, ampliamente distribuidos en la naturaleza, especialmente en la tierra y sustrato vegetal $(6,7)$. Estas especies son

\section{ABSTRACT}

It reports a case of hand onychomycosis, which was isolated repeatedly Sporothrix pallida and Trichophyton rubrum. We discuss the main agents of onychomycosis, the role of the environmental fungi and S.pallida isolation in this and other samples.

los agentes de la esporotricosis, la cual puede tener presentación linfocutanea, cutánea fija o diseminada (8).

Trabajos recientes han demostrado que $\boldsymbol{S}$. schenckii corresponde a un complejo de especies, en el cual se encuentran tres de importancia médica: $\boldsymbol{S}$. schenckii sensu stricto, $\boldsymbol{S}$. brasiliensis y $\boldsymbol{S}$. globosa, además de $\boldsymbol{S}$. mexicana y $\boldsymbol{S}$. pallida 0 albicans, aisladas principalmente del ambiente $(9,10)$.

El aislamiento de $S$. schenckii complex en casos de OM es excepcional, existiendo tan solo un reporte publicado en la literatura (11) y recientemente nuestro grupo aisló $S$. pallida en uña de pie y en el suelo del jardín donde la paciente realiza a diario sus actividades de jardinería (12).

El objetivo de este trabajo es presentar un caso de tiña unguium de mano donde se aisló repetidamente $S$. pallida y $T$. rubrum, ademas de discutir sobre el rol del primero en éste y en otro tipo de muestras. 
Aislamiento de Sporothrix pallida y Trichophyton rubrum en onicomicosis de mano - R. Cruz et al.

\section{Caso clínico}

Paciente de 65 años de edad, con antecedentes de DM II en tratamiento con hipoglicemiantes orales. Trabaja diariamente en labores de jardinería en su hogar, donde entra en contacto con tierra y sustrato vegetal.

Consulta en policlínico por presentar engrosamiento subungueal y cambio de coloración de las uñas de los dedos pulgar e índice izquierdo (Figura 1). Se le solicitó examen microscópico directo y cultivo de las lesiones. En el primero se informa moderada cantidad de micelio muy fino y escaso micelio con artroconidios. En el cultivo hubo desarrollo de $\boldsymbol{S}$. pallida y $\boldsymbol{T}$. rubrum. Se repitió la muestra del paciente en dos ocasiones, obteniéndose los mismos resultados. Se inició tratamiento con terbinafina $250 \mathrm{mg} /$ día por 12 semanas, con escasa respuesta clínica, por lo que se cambió tratamiento a itraconazol por 8 semanas, lograndose una respuesta satisfactoria hasta la mejoría.

\section{Estudio morfo-fisiológico de las cepas aisladas.}

\section{S.pallida:}

A partir de las colonias morfológicamente compatibles con Sporothrix $s p$. se realizaron resiembras en agar PDA (patata, $200 \mathrm{~g}$; glucosa, 10g; agar agar, $18 \mathrm{~g}$; agua destilada, $1000 \mathrm{ml}$ ), las que fueron incubadas a $26^{\circ} \mathrm{C}$. Para identificar los aislamientos, se consideraron tanto las características de las colonias (color de la superficie y el reverso, textura, velocidad de crecimiento y producción de exudados y pigmentos solubles), como las características morfológicas de las estructuras vegetativas y reproductivas (diámetro de las hifas y los conidióforos, forma, tamaño, ornamentación, disposición y coloración de los conidios). El estudio fisiológico fue realizado según Marimón et al. (9), evaluando el crecimiento en PDA a $30^{\circ} \mathrm{C}$ y $37^{\circ} \mathrm{C}$ por 21 días, y la asimilación de azúcares en agar base nitrogenado con sacarosa y rafinosa (13).

En los cultivos se desarrolló un hongo filamentoso de color blanquecino, cuyo color no varió a lo largo de la incubación (Fig 2). Al microscopio de campo claro (Zeiss ${ }^{\circledR}$ Axiostar Plus), se observaron hifas delgadas, hialinas, septadas y ramificadas, con abundantes conidios hialinos, ovoides, de 4-7 x 1,6$2,5 \mu \mathrm{m}$, en agrupaciones simpodiales en la región terminal del conidióforo (Fig. 3). En PDA las colonias midieron entre 50 y $60 \mathrm{~mm}$ diámetro, tanto a 30 como a $37^{\circ} \mathrm{C}$. Las pruebas de asimilación de azúcares fueron positiva para la sacarosa y negativa para la rafinosa. Todos estos resultados fueron compatibles con S. pallida 0 albicans.

\section{T. rubrum:}

Fue sembrado en agar Sabouraud (glucosa, 20g; peptona, $10 \mathrm{~g}$; agar-agar, $20 \mathrm{~g}$; cloranfenicol, $0,25 \mathrm{~g}$; agua destilada, $1000 \mathrm{ml}$ ) y en agar lactrimel (harina de trigo, $14 \mathrm{~g}$; miel, $7 \mathrm{~g}$; leche de vaca desnatada, 14g; agar agar, $14 \mathrm{~g}$; cloranfenicol, 0,25 g; agua destilada, $1000 \mathrm{ml}$ ) por 15 días. Hubo desarrollo de colonias rojizas en anverso y reverso (Figura 4), de crecimiento rápido, aspecto finamente velloso que fue tomando un aspecto aterciopelado. La superficie presentó surcos radiales poco profundos y los bordes fueron netos y las prolongaciones radiales le dieron un aspecto desflecado. En la visualización microscópica se observaron microconidios piriformes 0 clavados (de 3-5,5 x 2-3,5 $\mu \mathrm{m}$ ), sésiles sobre las hifas, con macroconidios escasos (de 40-55 x 6- 7,5 ìm), clamidosporas intercalares, presencia de hifas en raqueta y ausencia de filamentos en espirales.

\section{DISCUSIÓN}

La OM es una infección frecuente y de difícil tratamiento, donde el diagnóstico etiologico es fundamental al momento de optar por una de las alternativas farmacológicas (14). Los aislamientos de hongos ambientales causantes de OM son cada vez más frecuentes, siendo predominantes especies pertenecientes a los géneros Acremonium, Fusarium y Scopulariopsis $(5,14)$, sin embargo, la literatura médica recoge un trabajo donde se describen casos de OM debidas a especies del género Sporothrix (15). Las especies del género Sporothrix asociadas a patología humana corresponden a S. schenckii sensu stricto, S. brasiliensis, S. globosa y S. Iuriei $(9,16,16,17)$. S. pallida es considerado un hongo ambiental aislado en una amplia variedad de sustratos, sin embargo se han reportado infecciones en felinos en Brasil (18), y recientemente una posible OM en uña de pie de una paciente en Chile (12). Modelos de infección en murinos han demostrado la baja patogenicidad de esta especie y la incapacidad de provocar infecciones subcutáneas o diseminadas, a diferencia de las otras especies del género $(19,20)$. La ausencia de conidios secundarios (con pigmentos 


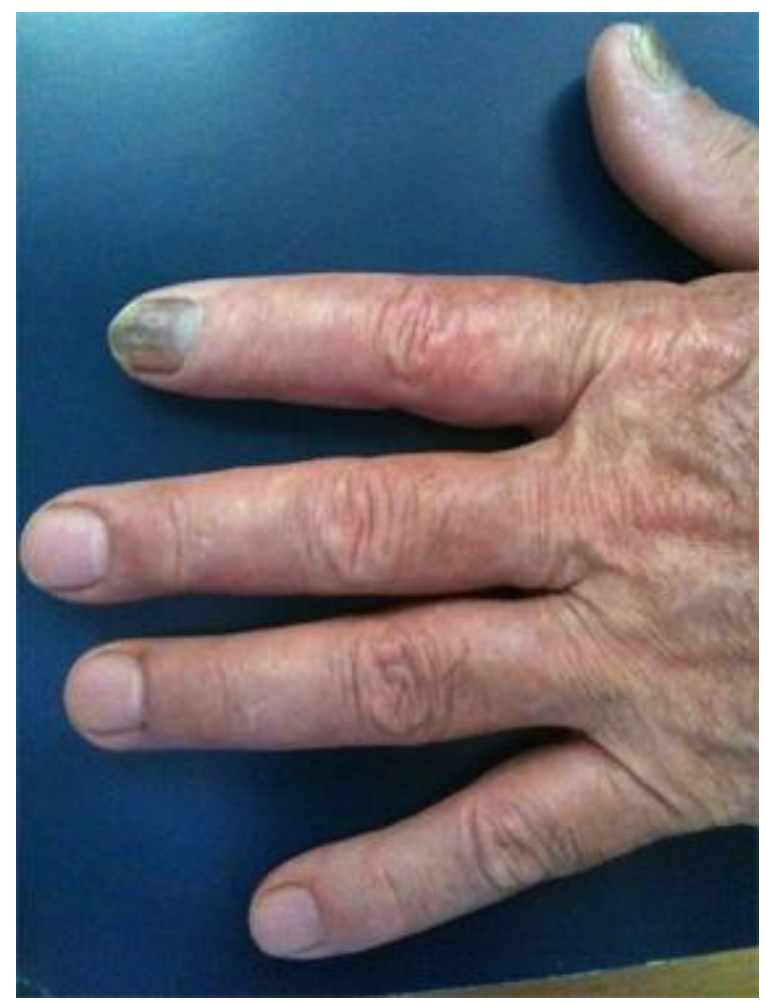

Figura 1. Onicomicosis de los dedos pulgar e índice de la mano izquierda

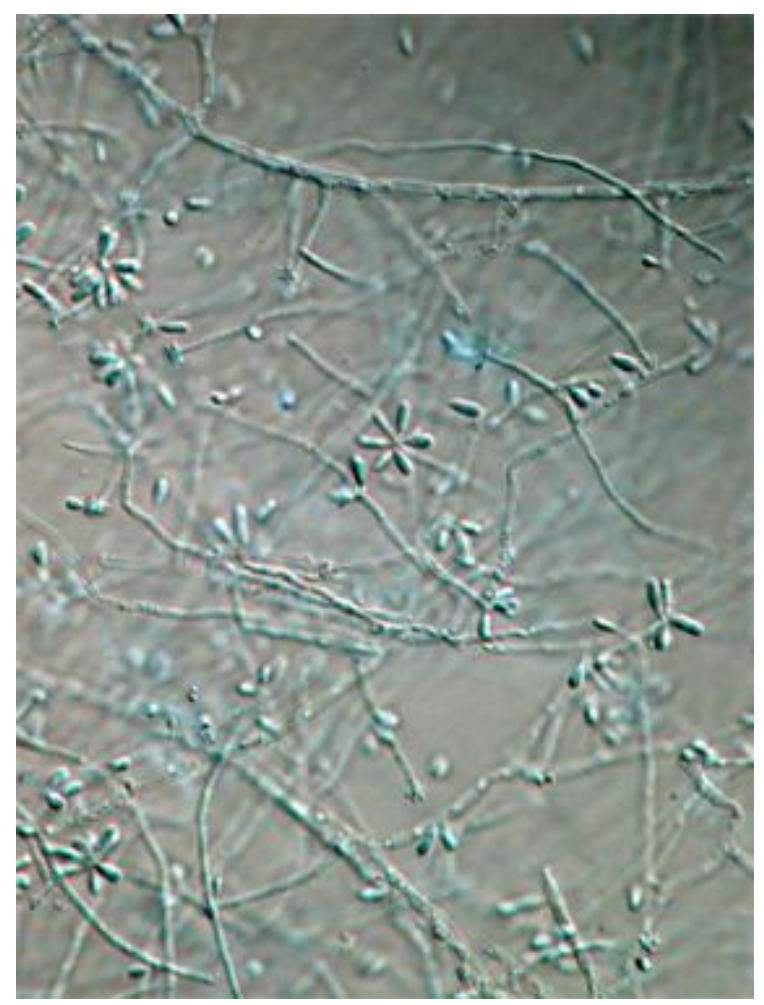

Figura 3. Conidioforo con microconidios terminales simpodiales. Azul de algodón 100X.

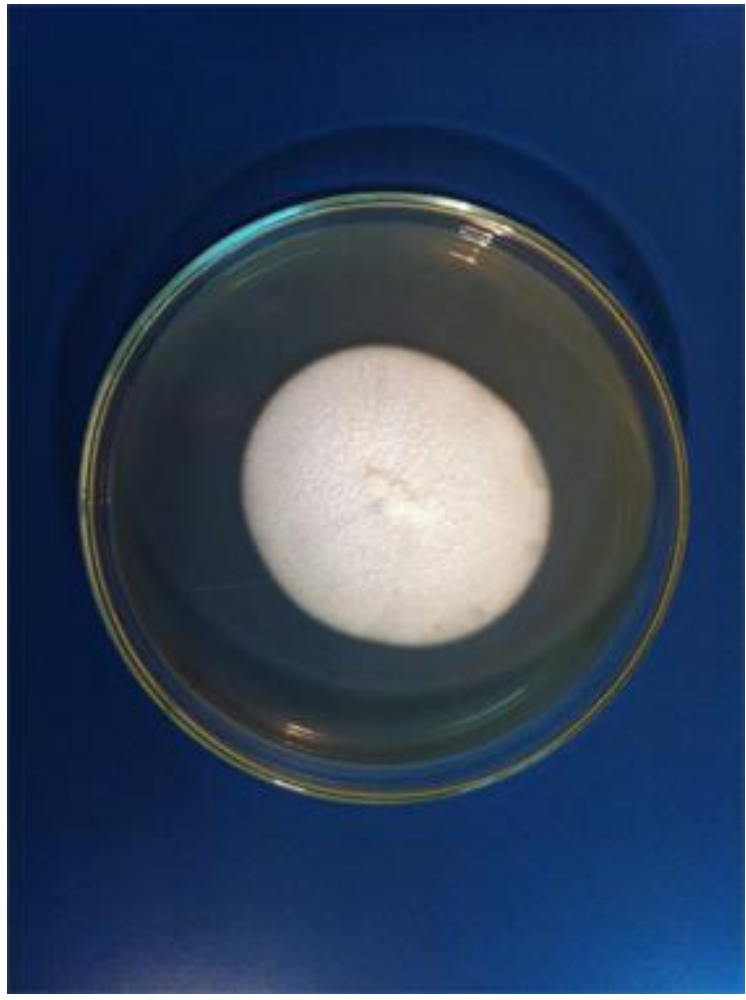

Figura 2. Colonia de Sporothrix pallida en agar PDA.

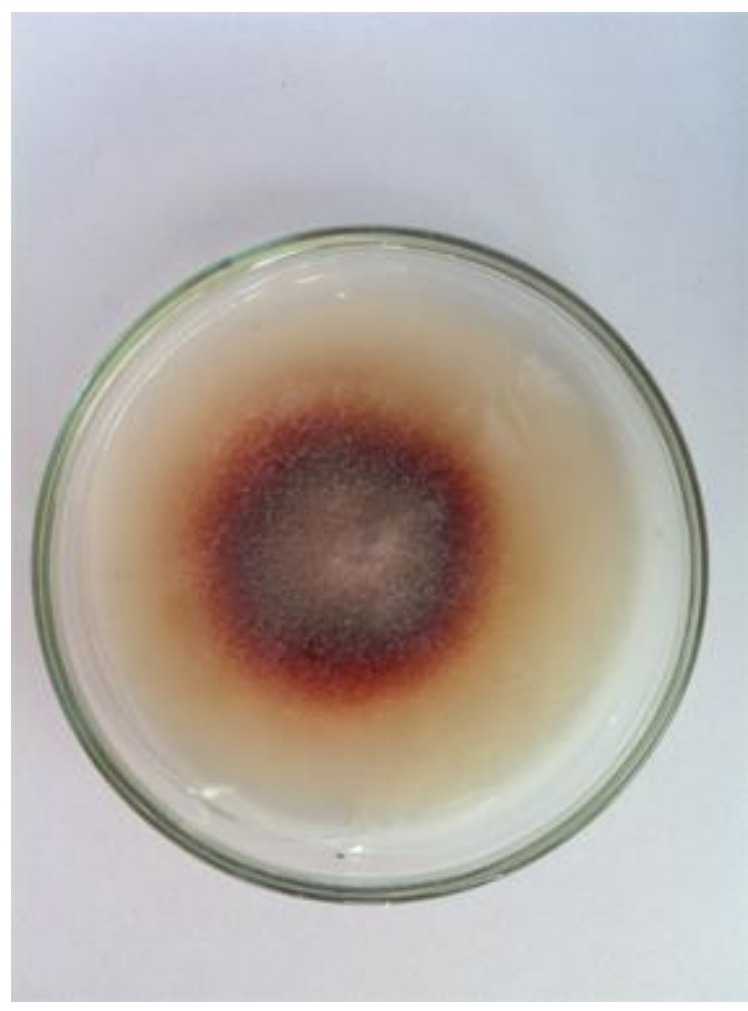

Figura 4. Colonia con pigmento púrpura de Trichophyton rubrum en agar lactrimel. 
Aislamiento de Sporothrix pallida y Trichophyton rubrum en onicomicosis de mano - R. Cruz etal.

melánicos) determina probablemente el bajo poder patogénico en mamíferos, con menor tolerancia a la radiación UV y a la acción de radicales libres, además de presentar menor resistencia a la fagocitosis $(19,20)$. El rol que tuvo S. pallida en la OM de la paciente no está claro, probablemente fue solo una colonización, sin embargo existe la posibilidad que haya participado en la infección de la uña. Apoya esto la mala respuesta a la terbinafina y la buena respuesta al itraconazol, situación descrita en el trabajo de sensibilidad realizado por Oliveira et al (18).

Marimon et al. (9) propusieron una clave morfofisiológica para diferenciar las especies clínicamente relevantes del género Sporothrix, basada en la pigmentación de los conidios, el crecimiento en PDA a diferentes temperaturas y la asimilación de azúcares. Este método realizado para identificar nuestra cepa, tiene la ventaja de ser económico y fácil de implementar por los laboratorios de micología. Sin embargo, la secuenciación de los genes de la calmodulina y de la $\alpha$-tubulina es una herramienta imprescindible para la correcta identificación de especies del género, debido a que, gracias a su especificidad, limita los errores derivados de la variabilidad morfológica que pueden presentar ciertos aislamientos $(9,17)$.

Aún queda bastante que estudiar sobre distintos aspectos del complejo Sporothrix, su patogenia y el rol de especies consideradas no patógenas en aislamientos superficiales como onicomicosis.

\section{REFERENCIAS}

1. Arenas R. (2004). Dermatofitosis. Arenas R, editor. Micología Médica llustrada, 1a ed. Ciudad de México: Editorial McGraw-Hill; 2004, p. 61-94.

2. Velasco M, García-Melgares L, Gimeno E, Roche E, Vilata J J. (2006) Dermatofitosis. Vilata J J, editor. Micosis Cutaneas, 1a ed. Madrid: Editorial Médica Panamericana 2006; p. 49-72.

3. Manzano-Gayosso P, Méndez-Tovar LJ, Arenas R, Hernández-Hernández F, Millán-Chiu B, TorresRodríguez J M, Cortés-González E, Fernández, R, López-Martínez R. (2011). Levaduras causantes de onicomicosis en cuatro centros dermatológicos mexicanos y su sensibilidad antifúngica a compuestos azólicos. Rev Iberoam Micol. 2011;28:32-5.
4. Mendoza N, Palacios C, Cardona N, Gomez L. (2012). Onicomicosis: afección común de difícil tratamiento. Rev Asoc Colomb Dermatol. 2012; 20( 2) :149-158.

5. Cavallera E, Asbati M. (2006). Onicomicosis por hongos filamentosos no dermatofitos. Dermatol Venez 2006; 44: 4-10.

6. Da Rosa AC, Scroferneker ML, Vettorato R, et al. (2005). Epidemiology of sporotrichosis: a study of 304 cases in Brazil. J Am Acad Dermatol 2005; 52: 451-459.

7. Mackinnon J E, Conti-Díaz I A, Gezuele E, Civila E, da Luz S. (1969). Isolation of Sporothrix schenckii from nature and considerations on its pathogenicity and ecology. Sabouraudia 1969; 7: 38-45.

8. Arenas R, Fernández R, Arce M. (2006). Micosis subcutáneas: esporotricosis, cromoblastomicosis y micetoma. Vilata JJ, editor. Micosis Cutáneas. 1a ed. Madrid: Editorial Médica Panamericana 2006, p. 131-47.

9. Marimon R, Cano J, Gené J, Sutton DA, Kawasaki M, Guarro J. (2007). Sporothrix brasiliensis, S. globosa, and S. mexicana, three new Sporothrix species of clinical interest. J Clin Microbiol 2007; 45: 3198-3206.

10. Cruz R, Vieille P,Oschilewski D. (2012). Aislamiento ambiental de Sporothrix globosa en relación a un caso clínico de esporotricosis linfocutanea. Rev Chil Inf 2012; 29(4): 401-405.

11. Conti-Díaz I. (1964). Estudio micológico de 85 casos de onicopatías. An Fac Med Montevideo 1964; 49(5-6): 535-540.

12. Cruz R, Vieille P, Cano JF, Stchigel A. Aislamiento de Sporothrix albicans y S. globosa a partir de muestras clínicas y ambientales de Chile. Trabajo en prensa.

13. Land GA, Vinton E C, Adcock G B, Hopkins J M. (1975). Improved auxanographic method for yeast assimilations: a comparison with other approaches. J Clin Microbiol 1975; 2: 206-17.

14. Cruz R, Ponce E, Calderón L, Delgado N, Vieille P, Piontelli E. (2011). Micosis superficiales en la ciudad de Valparaíso, Chile: Período 2007-2009. Rev Chil Inf 2011;28(5):40-409. 
15. Ferreira G, Oliveira P, Messias A, Augusto A, Burger E, Pires de Camargo Z. (2013). Characterization of virulence profile, protein secretion and immugenicity of different Sporothrix schenckii sensu stricto isolates compared with $S$. globosa and S. brasiliensis species. Landes Bioscience 2013; 4(3): 1-9.

16. Marimon, R, Gené J, Cano J, Trilles L, Dos Santos Lazera M, Guarro J. (2006). Molecular phylogeny of Sporothrix schenckii. J Clin Microbiol 2006; 44:32513256.

17.Romeo 0, Scordino F, Criseo G. New insight into molecular phylogeny and epidemiology of Sporothrix schenckii species complex based on calmodulinencoding gene analysis of Italian isolates. Mycopathologia.2010; 172(3):179-86.

18. Oliveira D, Markus Lopes P, Spander T, Mahl C, Tronco-Alves G, Lara V, Santurio J, Hartz Alves S. (2011). Antifungal Susceptibilities of Sporothrix albicans, $S$ brasiliensis, and $S$ luriei of the $S$. schenckii complex identified in Brazil. J Clin Microbiol 2011; 49(8): 3047-3049.
19. Arrillaga I, Capilla J, Fernandez A, Fariñas F, Mayayo E. (2010). Diferencias en la patogenicidad del complejo de especies Sporothrix en un modelo animal. Patología 2010; 48(2): 82-87.

20. Arrillaga-Moncrieff I, Capilla J, Mayayo E, Marimon R, Marine M, Gené J, et al. (2009). Different virulence levels of the species of Sporothrix in a murine model. Clin Microbiol Infect 2009; 15(7): 651-655

\section{CONFLICTO DE INTERESES}

Los autores declaran no tener conflictos de intereses. 